\title{
Geospatial technology in environmental health applications
}

\author{
Fazlay S. Faruque
}

Received: 26 March 2019 / Accepted: 29 March 2019

(C) Springer Nature Switzerland AG 2019

\section{Background}

The associations of environmental factors with human health and well-being now can be more precisely analyzed than before. Several multidisciplinary achievements advanced our understanding of the continuum of "environment and health outcomes." Investments in multidisciplinary initiatives led to the development of many new tools that can pinpoint environmental factors, human exposure, and health outcomes on a wide range of scales - from global to even an individual. As environmental factors and human interactions cannot be completely examined without accounting for their spatial components and relationships, the improvements in geospatial data quality, technology, and analytical tools are playing a critical role to advance our understanding of environmental factors affecting human health and well-being. However, at the same time, researchers must be aware of the limitations of spatial data and tools, while conducting their studies.

This special issue covers a wide range of geospatial health-related topics and methods including the climate change, neglected tropical diseases, vector-borne diseases, smartphone technology, healthcare utilization, health disparities, air quality assessment, asthma, water

This article is part of the Topical Collection on Geospatial Technology in Environmental Health Applications

\section{F. S. Faruque $(\bowtie)$}

University of Mississippi Medical Center, Jackson, MS, USA

e-mail: ffaruque@umc.edu quality assessment, antimicrobial resistance, and machine learning.

After intense reviews and revisions, the following 23 papers were selected for publication. While in many instances, the topics and methodologies of the papers significantly overlap, a brief discussion about the papers is provided below under loosely aggregated categorizations.

\section{Research topics}

Climate

Extreme weather and related phenomena appear to be rising in frequency and intensity which pose growing health risks to human populations.

Liss and Naumova (2019) conducted spatio-temporal analyses to examine the association between hospitalizations due to heat stroke in older adults in the United States with respect to heatwave sequence, time of arrival, and regional climate. Analyzing 16 years of daily hospitalization records, the authors found substantial differences in heat-related hospitalizations and response to heatwaves in different climate regions of the USA. As heatwaves are one of the major manifestations of the growing events of extreme weather, the authors suggested that the findings of this study could be useful for prevention as well as for decision support framework for heat-related medical care, which would be more essentials in the coming years.

Wrable and her colleagues (Wrable et al. 2019) analyzed 8 years of monthly reported schistosomiasis to 
identify environmental variables of this disease. They assessed the spatio-temporal associations between schistosomiasis disease rates and three remotely sensed environmental variables: land surface temperature, normalized difference vegetation index, and accumulated precipitation. They found the schistosomiasis infection rates to vary with distinct seasonal patterns. They also found the direction and strength of the associations to vary with remotely sensed parameters, influenced by the climate zones.

Rodgers et al. (2019) developed ecological niche models (ENMs) for the distribution of visceral leishmaniasis (VL) and sand fly species in Bahia state, Brazil. They used a number of remote sensing derived parameters and indices, and were able to distinguish the maximum contributing variables to the models for VL. The authors were also successful in identifying suitable areas for VL and/or sand fly. Their findings could guide VL control programs with an improved preventative model.

Tourre and his colleagues (Tourre et al. 2019) examined the impact of climate change on malaria transmission by using rainfall and temperature indices to predict future malaria incidence under different climate change scenarios in West Africa. The authors concluded that the predicted increase in temperature could limit the malaria transmission dynamics in the Sahel region of Africa. Meanwhile, the relatively lower temperature in southern Europe could attract the vectors to potentially spread malaria in Europe.

Healthcare pattern and disparities

With the increasing availability of spatially tagged healthcare data, geospatial analyses can reveal underlying healthcare utilization patterns and also disparities if that exists.

Jia and his colleagues (Jia et al. 2019a, b) conducted a comprehensive study across demographic, socioeconomic, geographic, and health insurance subgroups of patients to understand patients' travel behavior for seeking hospital care. Their study revealed that patients' age, race, SES, urbanicity of residence, payment option, and insurance could contribute to different patterns of travel behavior.

Casas and Delmelle (2019) studied the landscapes of healthcare utilization during a dengue fever outbreak in an urban environment in Colombia. They used three indices to examine the utilization patterns - utilization rate, travel time usage index, and travel time index.
Their study revealed that dengue patients were willing to travel various distances to receive their needed healthcare. As the understanding of healthcare utilization patterns could help to identify overused and underused healthcare services, similar studies could assist in optimizing healthcare services.

Jia et al. (Jia et al. 2019a, b) developed a populationbased hospital service areas delineation method to assist with the planning and optimization of hospital resource allocation. In their study area in Florida, they found that the difference in the ratios of hospital beds to the population between the most over- and under-served HSAs was approximately 60 times. They also identified significant clusters of high and low ratios in Miami and Jacksonville metropolitan areas, respectively.

Using data from County Health Rankings and transportation infrastructure measures, Chi et al. (2019) examined how county-level health was associated with access to airports and highways across the counties in the southeastern USA. Adapting the neoclassical growth model and using the composite County Health Rankings, the authors found that airports had a positive effect on county health. They also found that the higher proportions of the black population in the black belt counties lowered their overall health ranking.

Air quality, monitoring, and diseases

According to WHO (2018), 9 out of 10 people breathe air containing high levels of pollutants. Air pollution has become the deadliest form of pollution and the fourth leading risk factor for premature deaths worldwide (World Bank 2016), and PM2.5 is one of the most damaging ambient air pollutants, causing most of the premature deaths worldwide (WHO 2018). Since there is a shortage of PM monitoring facilities, there have been continuous attempts to estimate ground-level PM2.5 from satellites' total column aerosol optical depth (AOD) by incorporating other relevant data and applying new methods.

In spite of continuing national and international efforts, asthma is still a major global health problem. According to the 2016 Global Burden of Disease (GBD), there were 339.4 million people worldwide affected by asthma, which is a $3.6 \%$ increase in agestandardized prevalence since 2006 . The same report estimated that asthma killed more than 1000 per day in 2016 (GAN 2018). It is well established that air 
pollutants, particularly PM2.5 and ozone, exacerbate asthma and other respiratory diseases (Faruque et al. 2014).

Al-Hamdan et al. (2019) developed new regression models to correlate MODIS derived AOD products with ground-measured PM2.5. They included NLDAS data to account for the meteorological variables in their estimation of ground-level PM2.5 from AOD. While evaluating the suitability of their models to estimate groundlevel PM2.5, they found that the relationships varied for different AOD products and also for different regions in the USA.

Kazemi-Beydokhti and his colleagues (KazemiBeydokhti et al. 2019) examined the distribution of existing multi-pollutant air quality monitoring stations in Tehran, Iran. They discussed why Tehran needed a more efficient monitoring system to more precisely learn about the distribution of air pollution. The authors integrated hybrid multi-criteria decision-making (MCDM) theories in their spatial analysis to identify the optimum locations for new stations to generate more accurate air quality scenarios for the city. Authors also evaluated the stability and reliability of their output results to identify locations for deploying new monitoring stations.

Pratt et al. (2019) examined the possible impact of elevated ozone associated with smoke (EOAS) on pediatric asthma in different regions of the USA. Using a Monte Carlo approach, they conducted a quantitative burden assessment (BA) to estimate the median number of excess pediatric asthma emergency department (ED) visits that might be attributed to EOAS among children with asthma in the continental USA between 2005 and 2014. The authors found a significant increase in pediatric asthma ED visits associated with exposure to enhanced ozone from smokes. The authors pointed out that although the severity and frequency of wildfire most likely would continue to increase, the impacts of wildfire-originated ozone on cardiopulmonary health did not receive adequate attention in research.

Oyana and his colleagues (Oyana et al. 2019) assessed the impact of PM2.5 exposure on pediatric asthma health. Utilizing 11 years of data from a cohort study, the authors observed a higher impact of PM2.5 on pediatric asthma during the initial period/first years of a child's life. These authors also found that along with the level of exposure to PM2.5, the impacts varied by age, race/ethnicity, and insurance, which contributed to asthma health disparities among children.
Mudiyanselage and Tripathi (2019) employed different methodologies to examine the associations between asthma/COPD morbidity and their determinants. By analyzing individually and in combination, they explored the potential risk factors per meteorological factors, direct and indirect factors of air pollution, socioeconomic factors, and characteristics of the physical environment. They found that relative humidity, proximity to roads, road density, use of firewood, and elevation played a vital role in predicting morbidity from asthma and COPD.

Chang et al. (2019) examined associations between asthma morbidity and local ambient air pollution for an area where the levels of pollution were relatively low. They conducted a time series analysis of asthma hospital admissions and fine particulate matter pollution (PM2.5) in central Mississippi for the period of 2003 to 2011. Their study found an estimated amount of 7.2 increase in daily all-age asthma emergency room admissions per $10 \mu \mathrm{g} / \mathrm{m}^{3}$ increase in the 3-day average of PM2.5 levels.

\section{Water and soil}

Geospatial technology assessing water quality, whether groundwater or surface water, has been one of the earlier applications in the area of environmental health. As the water for human consumption comes from diverse sources - aquifers, streams, rivers, lakes, etc., assessing and maintaining its quality is challenging. Groundwater quality assessment can be even more complicated as its sources of pollution, and the process of attenuation impose more difficulties to portray the real scenario. While WHO states that water safety and quality are fundamental to human development and well-being, various reports show that globally, a significant number of people are still vulnerable to unhealthy water consumptions. Geospatial technology also has been playing a critical role in identifying health-related environmental issues in soils in different complex settings including aquatic and coastal environments.

Jalali et al. (2019) examined different methods to assess groundwater quality of an aquifer in Iran. The authors highlighted the advantages of multivariate statistical and geostatistical methods to compile the hydrogeochemical properties of groundwater properties. They analyzed seven hydro-geochemical parameters for the Saveh aquifer, Markazi province, Iran. The authors 
suggested that their findings could assist in improving groundwater quality assessment studies in other regions.

Saha and Paul (2019), in their groundwater quality assessment study, examined multiple techniques to identify better approaches. They suggested that the interdisciplinary techniques and framed methodology they applied could result in information more suitable for public health interpretations and adaptations.

Raju et al. (2019) examined the concentration of dissolved mercury in drinking water in their study area in Lucknow, India. They discussed how a probability kriging method could be applied to assess the human health risk due to mercury in drinking water resources. They generated prediction maps for $\mathrm{dHg}$ concentration and also identified $\mathrm{dHg}$ hotspots in the study area. The authors suggested that this study, being conducted within one of the most densely populated and active areas in the world, could be a premise to other human health risk assessments in a complex area with both natural and manmade contributions to the environment.

Griffin and his colleagues (Griffin et al. 2019) from the USGS analyzed antibiotic resistance genes in coastal sediments and soils along the eastern seaboard of the USA, which was the first study to address the occurrence and baseline of antibiotic resistance genes in soil and sediments in this region. They identified the widespread distribution of various antibiotic resistance genes across the study area. The authors suggested that along with the anthropogenic contributions, it is critical to understand the role that natural processes play on the occurrence and distribution of antibiotic resistance in microbial populations to minimize health risks associated with exposures. It should be noted that in recent years, the antibioticresistant microorganisms have been recognized as one of the greatest global public health threats.

\section{Smartphone applications}

The ubiquity of smartphones, nearly across all socioeconomic statuses, provided a great opportunity for both way communications between the individuals and the healthcare professionals. Smartphone applications, coupled with geospatial technology, are also presenting extraordinary opportunities for a variety of participatory disease control programs when accurate location, specific information, and quick response all are essentials.

Babu and his colleagues (Babu et al. 2019) developed two smartphone-based geospatial applications, MOSapp and DISapp, with an objective to support geospatially enabled early warning and adaptive response system (EWARS) for dengue control. The authors demonstrated how these applications could incorporate provisions for geospatially tagged, real-time data from both the community as well from the front-line public health workers. The authors also introduced a new mosquito abundance measure, the mosquito perception index (MPI), to implement an easier crowdsourcing environment for quicker responses. With the increasing use of smartphone-based applications, the proposed approach could effectively contribute to participatory disease surveillance.

\section{Machine learning}

Due to the diverse and complex nature of data involved in health studies, machine learning has been very effective in many health-related studies. The machine learning approach is expected to increase even more to examine the obscured underlying relationships and assist in addressing many multifaceted health-related issues.

Wu et al. (2019) combined remotely sensed and in situ observation data to estimate PM2.5 concentrations useful for health impact studies. Using several machine learning tools, they studied the temporal morphology of the PM2.5 annual cycle in East Asia. The authors identified the underlying meteorological factors and surface variables that are associated with temporal patterns of PM2.5 in different regions in East Asia.

Lary et al. (2019) implemented 20 different machine learning approaches to estimate student learning outcomes across all campuses in a large urban independent school district in Texas. Using their machine learning approach, the authors found that the number of days students were absent from school was a key factor in estimating the student learning outcomes, and one of the most important factors in estimating the number of days a student was absent was asthma. The authors concluded that this type of machine learning approach could build predictive models of the absenteeism which can help to provide insights into related underlying causes.

Zewdie et al. (2019) applied a number of machine learning methods to predict the daily ambrosia pollen in the atmosphere of Tulsa. They identified the most useful parameters in estimating Ambrosia pollen and ranked the performance of the machine learning methods.

Nathan and Lary (2019) utilized a combination of two techniques, the domain-filling with Lagrangian trajectories and the self-organizing map (SOM) to 
accurately identify multi-species hydrocarbon signatures and their responses to the surrounding environment. As properly identifying the hydrocarbon signatures, particularly in a multi-species environment, is critical for health and environmental impact assessment, the authors expect this study to be useful for other health impact analysis as well as for regulatory policymaking.

\section{Conclusions}

While about $23 \%$ of all global deaths are linked to the environment (Prüss-Üstün and Neira 2016), while scientists are discovering how environmental factors can cause epigenetic changes leading to health problems (Bollati and Baccarelli 2010) and while population growth and developmental thrusts continue to generate pressure on the environment, an understanding of environmental factors and human interactions is critical for making fruitful steps. Geospatial technology is now playing a pivotal role in understanding those environmental factors and processes (Faruque 2018; Faruque and Finley 2016; Maantay and McLafferty 2011). However, in the coming years, the role of geospatial technology is expected to be even much more efficient and effective bringing environmental health information closer to health professionals. This special issue hopefully will generate interests among the readers to move forward on that path contributing to improving our health and wellbeing.

Acknowledgements I appreciate the patience of the authors as the manuscripts went through intense reviews and revisions taking much more time to publish than anticipated. Reviewers have done a tremendous job contributing their valuable time to provide detailed comments and suggestions to the authors. The Springer staff members provided excellent support from the beginning without which this publication would not have materialized. I would also like to thank Professor Bruce Wiersma, the Chief Editor of EMAS, for his very timely suggestions. Finally, I acknowledge the Council and the Commission of the International Society for Photogrammetry and Remote Sensing (ISPRS), and my colleagues of the ISPRS Working Group on Environment and Health for supporting the research themes which are reflected in this special issue of EMAS.

\section{References}

Al-Hamdan, M., Crosson, W., Burrows, E., Coffield, S., Crane, B., \& Barik, M. (2019). Development and validation of improved PM2.5 models for public health applications using remotely sensed aerosol and meteorological data.
Environmental Monitoring and Assessment. https://doi. org/10.1007/s10661-019-7414-3.

Babu, A., Niehaus, E., Shah, S., Unnithan, C., Ramkumar, P., Shah, J., Binoy, V., Soman, B., Arunan, M., \& Jose, C. (2019). Smartphone geospatial apps for dengue control, prevention, prediction and education: MOSapp, DISapp and the mosquito perception index (MPI). Environmental Monitoring and Assessment. https://doi.org/10.1007 /s10661-019-7425-0.

Bollati, V., \& Baccarelli, A. (2010). Environmental epigenetics. Heredity, 105(1), 105-112.

Casas, I., \& Delmelle, E. (2019). Landscapes of health care utilization during a dengue fever outbreak in an urban environment of Colombia. Environmental Monitoring and Assessment. https://doi.org/10.1007/s10661-019-7415-2.

Chang, H., Pan, A., Waller, L., Lary, D., Zhang, L., Brackin, B., Finley, R., \& Faruque, F. (2019). Time series analysis of satellite-derived fine particulate matter pollution and asthma morbidity in Jackson, Mississippi. Environmental Monitoring and Assessment. https://doi.org/10.1007 /s10661-019-7421-4.

Chi, G., Shappley, D., Yang, T., \& Wang, D. (2019). Lost in the black belt south: health outcomes and transportation infrastructure. Environmental Monitoring and Assessment. https://doi.org/10.1007/s10661-019-7416-1

Faruque, F. (2018). Remote sensing and geospatial technologies in public health. ISPRS International Journal of GeoInformation, 7(8), 303. https://doi.org/10.3390/ijgi7080303.

Faruque, F., \& Finley, R. (2016). Geographic medical history: advances in geospatial technology present new potentials in medical practice. The International Archives of the Photogrammetry, Remote Sensing and Spatial Information Sciences, XLI-B8, 191-195.

Faruque, F., Li, H., Williams, W., Waller, L., Brackin, B., Zhang, L., Grimes, K., \& Finley, R. (2014). GeoMedStat: an integrated spatial surveillance system to track air pollution and associated healthcare events. Geospatial Health, 8(3), 631646.

GAN. (2018). The global asthma report 2018. Auckland: Global Asthma Network http://globalasthmareport.org/Global\%20 Asthma\%20Report\%202018.pdf. Accessed 12 Mar 2019.

Griffin, D., Benzel, W., Fisher, S., Focazio, M., Iwanowicz, L., Loftin, K., Reilly, T., \& Jones, D. (2019). The presence of antibiotic resistance genes in coastal soil and sediment samples from the eastern seaboard of the United States. Environmental Monitoring and Assessment. https://doi. org/10.1007/s10661-019-7426-z.

Jalali, M., Karami, S., \& Marj, A. (2019). On the problem of the spatial distribution delineation of the groundwater quality indicators via multivariate statistical and geostatistical approaches. Environmental Monitoring and Assessment. https://doi.org/10.1007/s10661-019-7432-1.

Jia, P., Wang, F., \& Xierali, I. (2019a). Differential effects of distance decay on hospital inpatient visits among subpopulations in Florida, US. Environmental Monitoring and Assessment. https://doi.org/10.1007/s10661-019-7409-0.

Jia, P., Shi, X., \& Xierali, I. (2019b). Teaming up census and patient data to delineate fine-scale hospital service areas and identify geographic disparities in hospital accessibility. Environmental Monitoring and Assessment. https://doi. org/10.1007/s10661-019-7413-4. 
Kazemi-Beydokhti, M., Abbaspour, R., Kheradmandi, M., \& Bozorgi-Amiri, A. (2019). Determination of the physical domain for air quality monitoring stations using the ANPOWA method in GIS. Environmental Monitoring and Assessment. https://doi.org/10.1007/s10661-019-7422-3.

Lary, D., Lary, M., Allsopp, L., \& Sterling, D. (2019). Using machine learning to examine the relationship between asthma and absenteeism. Environmental Monitoring and Assessment. https://doi.org/10.1007/s10661-019-7423-2.

Liss, A., \& Naumova, E. (2019). Heatwaves and hospitalizations due to hyperthermia in defined climate regions in the conterminous United States. Environmental Monitoring and Assessment. https://doi.org/10.1007/s10661-019-7412-5.

Maantay, J., \& McLafferty, S. (2011). Editorial. Geospatial analysis of environmental health (Vol. 4). Berlin: Springer Science \& Business Media.

Mudiyanselage, R., \& Tripathi, N. (2019). Geostatistical predictive modelling for asthma and chronic obstructive pulmonary disease using socioeconomic and environmental determinants. Environmental Monitoring and Assessment. https://doi.org/10.1007/s10661-019-7417-0.

Nathan, B., \& Lary, D. (2019). Combining domain filling with a self-organizing map to analyze multi-species hydrocarbon signatures on a regional scale. Environmental Monitoring and Assessment. https://doi.org/10.1007/s10661-019-74299.

Oyana, T., Podila, P., \& Relyea, G. (2019). Effects of childhood exposure to PM2.5 in a Memphis pediatric asthma cohort. Environmental Monitoring and Assessment. https://doi. org/10.1007/s10661-019-7419-y.

Pratt, J., Gan, R., Ford, B., Brey, S., Pierce, J., Fischer, E., \& Magzamen, S. (2019). A national burden assessment of estimated pediatric asthma emergency department visits that may be attributed to elevated ozone levels associated with the presence of smoke. Environmental Monitoring and Assessment. https://doi.org/10.1007/s10661-019-7420-5.

Prüss-Üstün, A., \& Neira, M. (2016). Preventing disease through healthy environments: a global assessment of the burden of disease from environmental risks. World Health Organization.

Raju, A., Singh, A., Srivastava, N., Singh, S., Jigyasu, D., \& Singh, M. (2019). Mapping human health risk by geostatistical method: a case study of mercury in drinking groundwater resource of the central ganga alluvial plain, northern India. Environmental Monitoring and Assessment. https://doi.org/10.1007/s10661-019-7427-y.

Rodgers, M., Bavia, M., Fonseca, E., Cova, B., Silva, M., Carneiro, D., Cardim, L., \& Malone, J. (2019). Ecological niche models for sand fly species and predicted distribution of Lutzomyia longipalpis (Diptera:Psychodidae) and visceral leishmaniasis in Bahia state, Brazil. Environmental Monitoring and Assessment. https://doi.org/10.1007 /s10661-019-7431-2.

Saha, P., \& Paul, B. (2019). Groundwater quality assessment in an industrial hotspot through interdisciplinary techniques. Environmental Monitoring and Assessment. https://doi. org/10.1007/s10661-019-7418-z.

Tourre, Y., Vignolles, C., Viel, C., Faruque, F., \& Malone, J. (2019). Malaria in Burkina Faso (West Africa) during the 21st century. Environmental Monitoring and Assessment. https://doi.org/10.1007/s10661-019-7410-7.

WHO. (2018). Key facts, ambient (outdoor) air quality and health. https://www.who.int/news-room/fact-sheets/detail/ambient(outdoor)-air-quality-and-health. Accessed 12 Mar 2019.

World Bank. (2016). The cost of air pollution: strengthening the economic case for action. Washington, DC, World Bank: License: Creative Commons Attribution CC BY 3.0 IGO. h t t p : / / d o c u m e n t s. w o r l d b a n k. org/curated/en/781521473177013155/pdf/108141REVISED-Cost-of-PollutionWebCORRECTEDfile.pdf. Accessed 12 Mar 2019.

Wrable, M., Kulinkina, A., Liss, A., Koch, M., Cruz, M., Biritwum, N., Ofosu, A., Gute, D., Kosinski, K., \& Naumova, E. (2019). The use of remotely sensed environmental parameters for spatial and temporal schistosomiasis prediction across climate zones in Ghana. Environmental Monitoring and Assessment. https://doi.org/10.1007 /s10661-019-7411-6.

Wu, D., Lary, D., Zewdie, G., \& Liu, X. (2019). Using machine learning to understand the temporal morphology of the PM2.5 annual cycle in East Asia. Environmental Monitoring and Assessment. https://doi.org/10.1007 /s10661-019-7424-1.

Zewdie, G., Liu, X., Wu, D., Lary, D., \& Levetin, E. (2019). Applying machine learning to forecast daily ambrosia pollen using environmental and NEXRAD radar parameters. Environmental Monitoring and Assessment. https://doi. org/10.1007/s10661-019-7428-x.

Publisher's note Springer Nature remains neutral with regard to jurisdictional claims in published maps and institutional affiliations. 